\title{
Observation on a case of Jervell and Lange-Neilsen syndrome in an adult
}

\author{
F. Furlanello, F. Maccà, and C. Dal Palù ${ }^{1}$ \\ From the Department of Internal Medicine, School of Medicine, University of Trieste, \\ Trieste, Italy
}

A case is described of true Fervell and Lange-Nielsen syndrome in an adult. Some relatives of the patient had QT lengthening, syncopal attacks, pigmented naevi on the skin and/or hypoacusia, and/or sudden death.

In a previous paper (Dal Palù and Furlanello, 1967) we discussed a patient who had recurring hyperkinetic syncopal crises triggered by emotional stress.

In this case the electrocardiogram recorded between the crises revealed a peculiar lengthening of the QT interval associated with a very slow repolarization wave and possible fusion of the TU waves, which appeared well defined in the ventricular postextrasystolic complexes.

Comparable anomalies of the electrocardiogram were observed and reported for the first time by Jervell and Lange-Nielsen (1957), then by Levine and Woodworth (1958), Romano, Gemme, and Pongiglione (1963), Fraser, Froggatt, and James (1964), Ward (1964), Jervell, Thingstad, and Endsjö (1966), Sánchez Cascos, Sánchez-Harguindey, and de Rábago (1969), and Gale et al. (1970). The tracings were obtained in children suffering with syncopal attacks. In many instances, these subjects were congenitally deaf mute or affected by severe auditory deficiencies and often they died quite suddenly of incontrollable ventricular fibrillation. Necropsy did not reveal morphological cardiopathies.

According to James (1967), similar clinical manifestations have been seenin certain strains of Dalmatian dogs. The breeder noticed that these genetically related animals were deafmute, presented chromatic anomalies of the coat, and died suddenly. Electrocardiogram showed a uniform lengthening of the QT interval; death was caused by ventricular fibrillation. These observations are thought-

\footnotetext{
1 Present address: Policlinico Borgo Roma, Verona,
} Italy. provoking because these animals can provide excellent material for comparative genetic studies.

Because of the symptoms and typical pattern of the electrocardiogram, the case presented below may be diagnosed as Jervell and Lange-Nielsen syndrome.

A thorough review of past and current published reports failed to reveal any cases of the syndrome diagnosed in adult life.

\section{Case report}

The patient is a 6I-year-old man affected from an early age by hearing deficiency (hypoacusia). At the age of 59 he had his first attack of syncope and was in hospital two weeks ago. The patient was admitted recently to his local hospital after a second attack. During this stay, syncope recurred frequently and were related as a cause-effect to ventricular fibrillation, as was shown by the electrocardiogram tracings (Fig. I). For these reasons the patient was sent to the intensive care unit of the University Hospital where he underwent repeated electrical defibrillation.

Later the patient was transferred to our medical ward for further investigation and management.

The family history and the genetic profile outlined in the pedigree (p. 65I) do not include the personal recollections of the parents because of their age.

The study revealed that several members of the family died suddenly during syncopal crises. Meanwhile the incidence of hearing defects and the presence of intradermal naevi were high.

The electrocardiograms obtained from the proband's sibs were characterized by typical lengthening of the QT interval, especially in Innocente's, Giuseppina's, and Maria's electrocardiograms, the latter showing also a slow repolarization wave with terminal fusion of the TU waves (see Fig. 4a-5b). Large intradermal naevi were found 


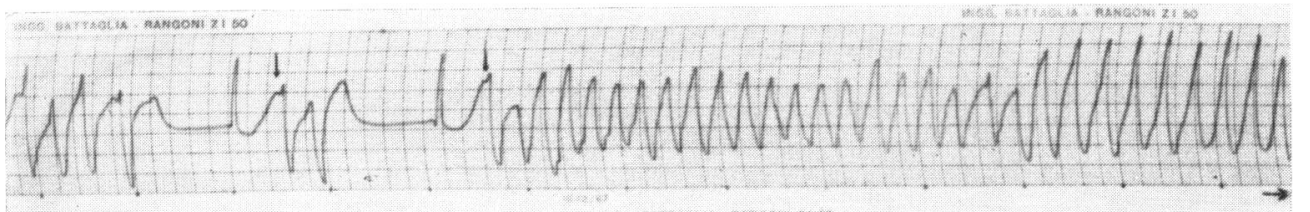

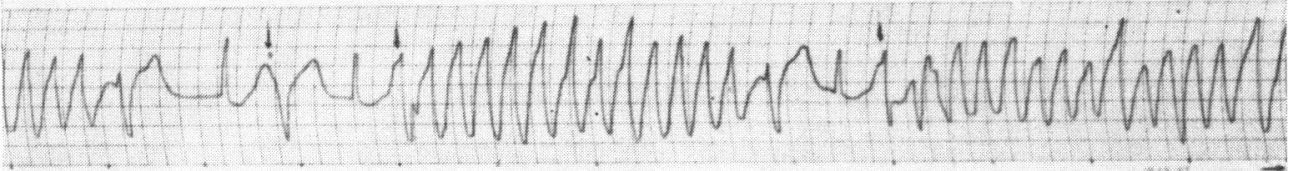

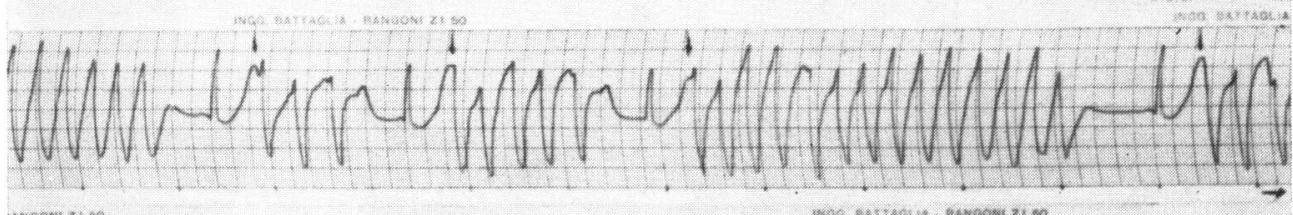

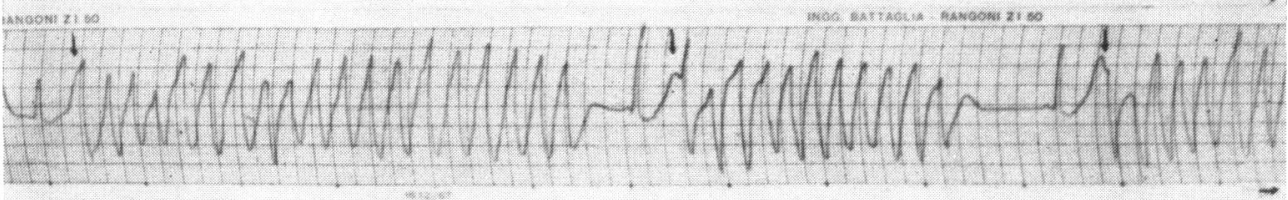

FIG. I Patient's electrocardiogram during a syncopal attack. Spontaneous repetitive ventricular fibrillation of short duration is initiated by a ventricular extrasystole during the vulnerable phase.

FIG. 2 and 3 Patient's electrocardiograms registered at monthly intervals between the crisis. Both are grossly abnormal. Note the length of the $T-U$ waves (freq. $77 / \mathrm{m}^{\prime}$; $Q-T U: 0^{\prime \prime} 57$, respectively $60 / \mathrm{m}^{\prime}$ and $\mathrm{o}^{\prime \prime} 6 \mathrm{I}$ ).

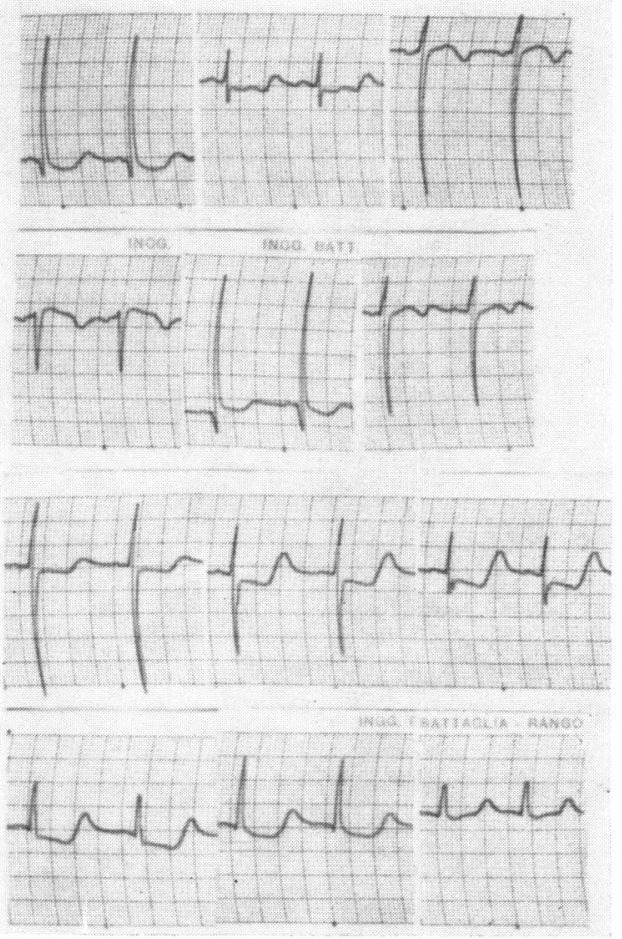

FIG. 3
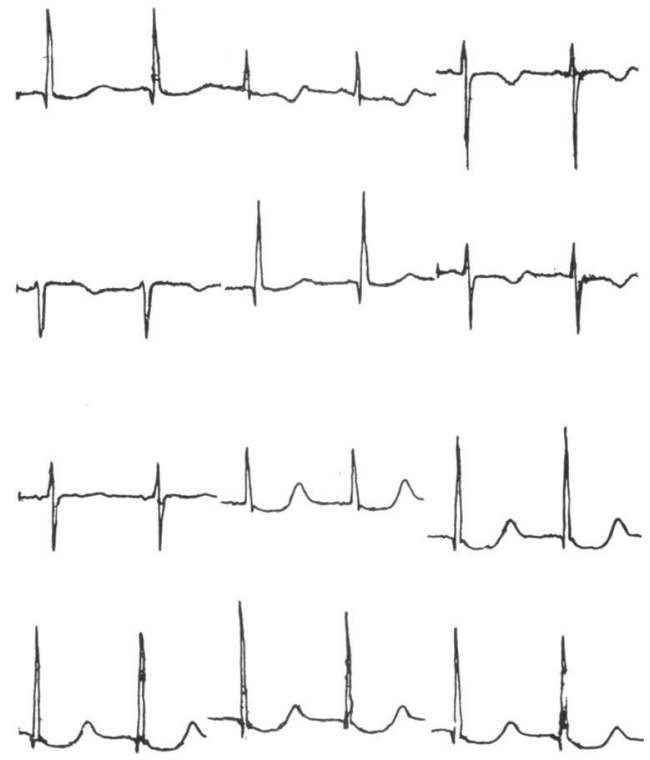


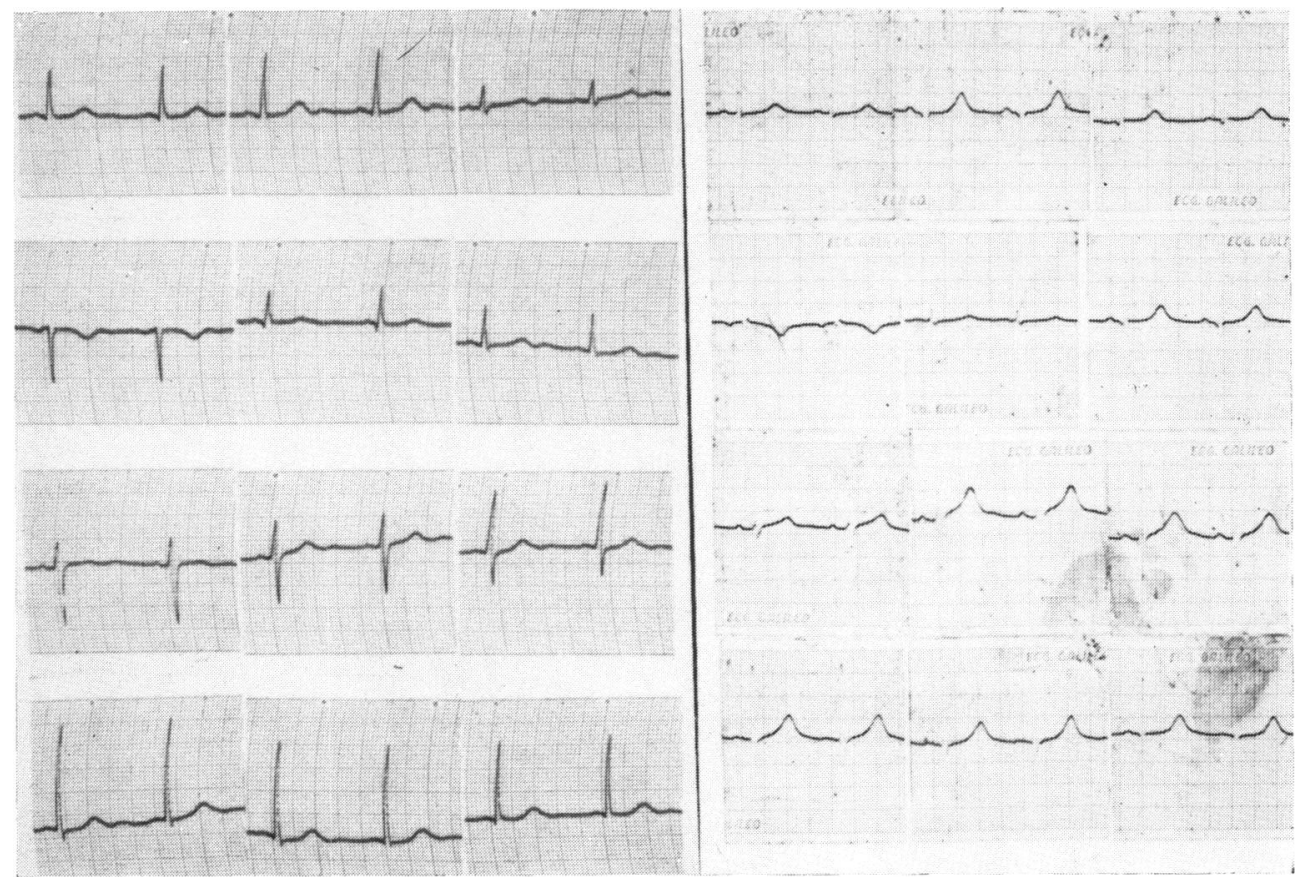

FIG. 4a, b Brother and sister of the patient. Both cardiograms are characterized by a lengthening of the $Q T$ interval. The brother's cardiogram freq. $60 / \mathrm{m}^{\prime}, Q T \mathrm{O}^{\prime \prime} 48$, prominent $U$ wave. The sister's freq. $7 I / m^{\prime}, Q-T O^{\prime \prime} 46$, prominent $U$ wave.

FIG. 5a, $\mathrm{b}$ The son and sister of the patient. The son's electrocardiogram is very similar to his father's: $Q T$ interval is only slightly prolonged. The sister's is grossly atypical:

$T U$ waves are fused. (freq. $45 / \mathrm{m}^{\prime}, Q-T U O^{\prime \prime} 62$.)
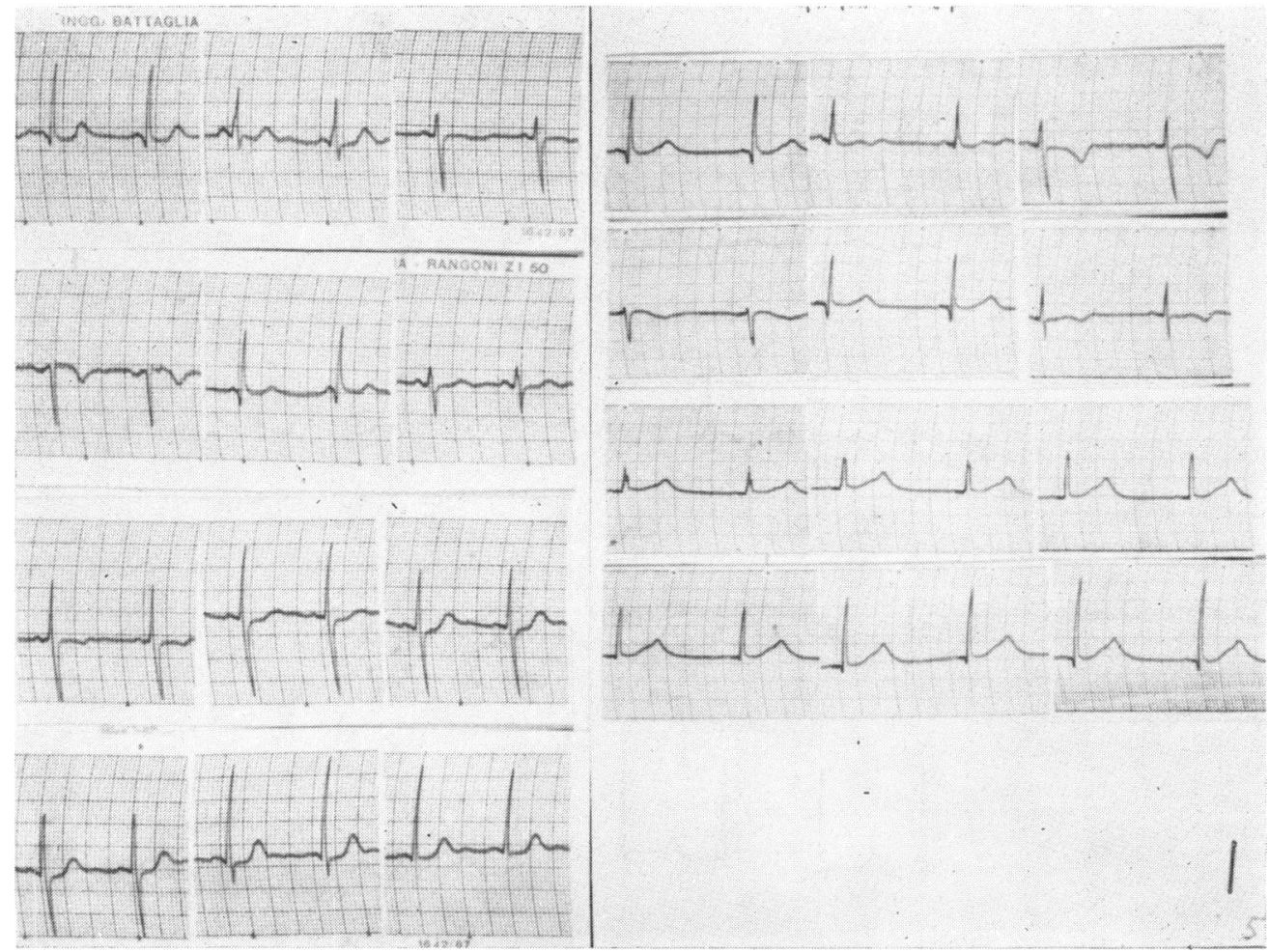


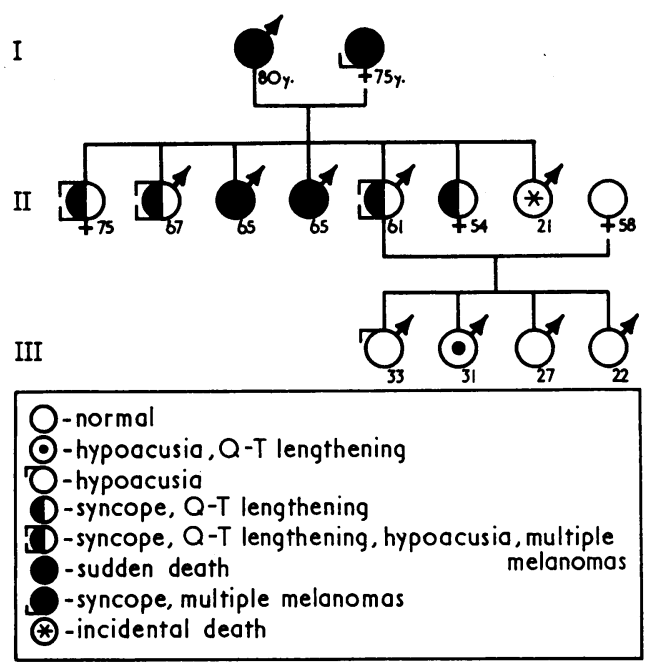

THE PEDIGREE

on inspection of the skin of some of the patient's sibs. The blood and serum studies gave normal results.

On admission the patient appeared anxious but his general status was satisfactory except for a moderate arterial hypertension of atherosclerotic type (180/90 $\mathrm{mmHg}$ ), with other clinical findings suggesting sclerosis of the aorta, supported by radiological evidence. Some naevi were noted on the skin, and one of them was large, located in the dorsal area.

The hearing defect was detected by audiometric evaluation (frequency: 4000 c.p.s.).

The clinical pathological studies of the blood and serum, including the evaluation of the electrolytic pattern $(\mathrm{K}+, \mathrm{Na}+, \mathrm{Cl}-, \mathrm{Ca}++)$, were normal.

The electrocardiograms shown in Fig. 2 and 3 were obtained at monthly intervals between the crisis of tachyarrhythmia. They revealed a conspicuous lengthening of the QT interval ( 0.58 sec; frequency: $70 / \mathrm{m}^{\prime}$ ).

The repolarization waves were abnormal: the fusion of the terminal phase of the $T$ wave with the $U$ wave is clear (see $D_{3}$ and aVF of the second electrocardiogram).

Moreover, there were signs of interatrial block and of left ventricular hypertrophy.

The patient, since his first attack, has been maintained on digoxin $0.25 \mathrm{mg}$ daily. His condition has improved and the electrocardiogram shows a decrease of the QT interval.

\section{Discussion}

The main clinical features shown by the case presented here, may be summarized as follows. (a) Recurring episodes of hyperkinetic syncopes; (b) pathological lengthening of the ventricular electrical systoles; (c) abnormal pattern of the repolarization wave which cannot be related to an electrolytic imbalance as revealed by serum studies; (d) high incidence of sudden death, syncopal attacks, QT lengthening, hypoacusia, and pigmented naevi among many relatives of the patients.

As far as ventricular fibrillation is concerned, there is no doubt about its close relation with the abnormal length of the QT interval which prolongs that vulnerable period of the cardiac cycle when occasional ectopic impulses may produce a chaotic repetitive paroxysmal arrhythmia, as has been proved by Delore (' $R$ in T' syndrome).

The treatment of choice for these functional cardiopathies - both in theory and as a result of our experience with this case - appears to be digitalization, which causes a shortening of the monophasic wave and therefore of the QT interval (Olley and Fowler, 1970).

Pathogenesis of the prolonged QT interval is not clear. Many hypotheses have been advanced, as an ionic imbalance of the membrane (which is not detectable by standard techniques of serum studies) or a congenital metabolic abnormality; both hypotheses may explain the conspicuous variability of the shape of the $T$ waves, which is a peculiar characteristic of all patients with this syndrome. Similar QT prolongation and $\mathrm{T}$ wave abnormalities may be produced by asymmetrical sympathetic stimulation of the ventricles (Yanowitz, Preston, and Abildskov, 1966).

The observation of QT lengthening in many relatives of our patient, associated with conspicuous hearing defect and intradermal naevi, is consistent with true Jervell and Lange-Nielsen syndrome, even if the pattern of inheritance is more consistent with Romano's and Ward's syndrome.

\section{References}

Dal Palù, C., and Furlanello, F. (1967). Crisi sincopali per tachicardia ventricolare di tipo 'prefibrillatorio' da causa emotiva: studio di un caso. Malattie Cardiovascolari, 8, 299.

Fraser, G. R., Froggatt, P., and James, T. N. (1964). Congenital deafness associated with electrocardiographic abnormalities, fainting attacks and sudden death. A recessive syndrome. Quarterly Fournal of Medicine, 33, 36r.

Gale, G. E., Bosman, C. K., Tucker, R. B. K., and Barlow, J. B. (1970). Hereditary prolongation of QT interval; study of two families. British Heart fournal, 32, 505 .

James, T. N. (1967). Congenital deafness and cardiac arrhythmias. American fournal of Cardiology, 19, 627.

Jervell, A., and Lange-Nielsen, F. (1957). Congenital deaf-mutism, functional heart disease with prolongation of the Q-T interval, and sudden death. American Heart fournal, 54, 59.

Jervell, A., Thingstad, R., and Endsjö, T. (1966). The surdo-cardiac syndrome. American Heart fournal, $72,582$. 
Levine, S. A., and Woodworth, C. R. (1958). Congenital deaf-mutism, prolonged QT interval, syncopal attacks and sudden death. New England fournal of Medicine, 259, 412.

Olley, P. M., and Fowler, R. S. (1970). The surdocardiac syndrome and therapeutic observations. British Heart fournal, 32, 467.

Romano, C., Gemme, G., and Pongiglione, R. (1963). Aritmie cardiache rare dell'età pediatrica. Clinica Pediatrica (Bologna), 45, 656.

Sánchez Cascos, A., Sánchez-Harguindey, L., and de Rábago, P. (1969). Cardio-auditory syndromes; cardiac and genetic study of 5 II deaf-mute children. British Heart fournal, 31, 26.
Ward, O. C. (1964). A new familial cardiac syndrome in children. Fournal of the Irish Medical Association, 54, 103.

Yanowitz, F., Preston, J. B., and Abildskov, J. A. (1966). Functional distribution of right and left stellate innervation to the ventricles: production of neurogenic electrocardiographic changes by unilateral alteration of sympathetic tone. Circulation Research, 18, 416.

Requests for reprints to Professor C. Dal Palù, Department of Internal Medicine, School of Medicine, Policlinico Borgo Roma, 37100 Verona, Italy. 